\title{
The Baby Boom and later life: is critical care fit for the future?
}

\author{
Richard Pugh ${ }^{1}$, Christian Subbe ${ }^{2}$, Chris Thorpe ${ }^{3}$, Tamas Szakmany ${ }^{4,5}$ \\ ${ }^{1}$ Glan Clwyd Hospital, Bodelwyddan, Wales, United Kingdom \\ ${ }^{2}$ School of Medical Sciences, Bangor University, Bangor, Wales, United Kingdom \\ ${ }^{3}$ Ys byty Gwynedd, Bangor, Wales, United Kingdom \\ ${ }^{4}$ Department of Anaesthesia, Intensive Care and Pain Medicine, Cardiff University, Cardiff, Wales, \\ United Kingdom \\ ${ }^{5}$ Critical Care Directorate, Royal Gwent Hospital, Newport, Wales, United Kingdom
}

\begin{abstract}
Populations around the world are ageing while in many developed countries the proportion of elderly patients admitted to critical care is rising. It is clear that age alone should not be used as a reason for refusing intensive care admission. Critical care in this patient group is challenging in many ways: with advancing age, several physiological changes occur which all lead to a subsequent reduction of physical performance and compensatory capacity, in many cases additionally aggravated by chronic illness. Subsequently, these age-dependent changes (with or without chronic illness) increase the risk for death, treatment costs and a prolonged length of intensive care and hospital stay. This review explores the potential of using co-morbidity and frailty to predict outcome and to help to make better decisions about critical care admission in the elderly.

The authors explore the challenges of using different frailty assessment tools and offer a model for holistic approach to answer these questions.
\end{abstract}

Anaesthesiology Intensive Therapy 2017, vol. 49, no 5, 441-444

Key words: elderly, frailty; critical care, outcome

Populations around the world are ageing [1]. In 1948, early in the post-war Baby Boom and the year in which the NHS was founded, $48 \%$ of the UK population died before the age of 65 . This proportion has now fallen to $14 \%$ and by 2040 , one in seven people in the UK will be aged over 75 years [2]. However, as recently observed by the UK Chief Medical Officer, although life expectancy is rising, overall morbidity in the UK appears to remain unchanged [3]. For healthcare and social systems, this ageing demographic poses an unprecedented challenge to deliver equitable care to appropriate patients.

In many, but not all developed countries, the proportion of elderly patients admitted to critical care is rising [4-6]. Historically, the oldest critically ill patients have received a lower intensity of therapy those who are younger [7]; however, recent trends suggest that the treatment intensity among elderly patients is also increasing and. perhaps as a consequence, some have observed a fall in the risk-adjusted hospital mortality for older ICU patients $[4,5]$.

\section{HEALTH TRAJECTORIES AMONG OLDER PATIENTS}

There are four major trajectories which have been identified among older decedents using medical claims data from more than 15 years ago [8]. The distribution of healthcare resource utilization for these four "final pathways to death" have been unchanged, with approximately $7 \%$ of patients experiencing a sudden event (trauma, cardiac arrest), 20\% a quick decline in function, typically within 6-8 weeks before the end-of-life secondary to cancer, $16 \%$ worsening organ failure due to relapse of their chronic disease and almost $50 \%$ having significant frailty with at least one diagnosis of stroke, dementia, Alzheimer's disease, Parkinson's disease or hip fracture [8]. 
The last group has the largest healthcare resource use during the final years of life and are often admitted to hospitals from nursing care facilities [8,9]. However, as symptom control and supportive care for the mainly neurocognitive dysfunctions improve, many from the baby-boomer population will be admitted from home, where they have become used to increased help and support from families or caregivers outside of the healthcare sector.

Critical care admission in this group varies considerably between western countries $[4,6]$. Interestingly, although critical care outcomes are generally improving amongst the elderly, resource limitations will almost certainly play a role, and there is likely to be variation in triage criteria applied to certain patient groups before admittance to the ICU [10]. It is clear that on the societal level, admission of elderly patients to the ICU provides diminishing return (from 22 QALYs in those under 65 years old to 4.1 QALYs to those over 80 years old) but also that chronological age is too crude a criterion by which to select ICU candidates [11].

\section{OUTCOMES FROM CRITICAL ILLNESS IN THE ELDERLY}

Age is a robust predictor of poorer short- and longterm outcomes following critical care admission $[4,12,13]$. However, the "mortality benefit of intensive care admission", meaning the difference in mortality between those admitted to intensive care and those refused admission, appears greatest among the oldest referrals to critical care [14]. Declining ICU admission purely on the grounds of age is unjustified, and data which can aid prediction of survival, short- and long-term resource requirements, functional dependence, and quality of life following critical care admission in older patients are, therefore, essential for informed discussion and decision-making for clinicians, patients and their families.

Examining age cohorts, of those aged 80 years and over admitted to an ICU, approximately half do not survive to hospital discharge; at 12 months, mortality rises to $70 \%$ and at 24 months to $80 \%[13,15]$. Strikingly, for those aged over 85 , the use of vasopressor therapy in ICU is associated with $97 \%$ mortality at 12 months, according to some investigators [13]. Comparing those aged 65 or over with those under 65 , 3-year survival among ICU survivors is significantly worse ( $57 \%$ versus $40 \%$ ), with the majority of the deaths in those over 65 occurring within the first month of discharge [11].

For longer-term survivors, mechanical ventilation is associated with a significantly higher level of disability among elderly patients twelve months after discharge when compared with a hospitalised cohort not requiring this level of support [16]. Sepsis too appears to lead to persistent cognitive and functional disability for years compared with hospitalisation for other reasons [17]. Despite this, quality of life following critical illness appears comparable to that of patients from age-matched controls. Thus, emotional wellbeing and social functioning often return to the expected range, despite physical limitations $[18,19]$.

\section{FRAILTY AND CRITICAL CARE}

Clearly, there is a spectrum of comorbidity and of pre-existing dependence and disability which will affect outcome from critical illness. However, the concept of "frailty" - described as "a condition characterized by loss of biological reserve and vulnerability to poor resolution of homeostasis following a stressor event" - is relatively new to critical care [20]. Although frailty is not exclusive to older populations, it becomes more common with age and is considered a phenomenon distinct from chronic illness. Among frail patients, recovery may be more protracted and incomplete, with persistent physiological instability and continued vulnerability to further stresses.

In the wider literature, a number of methods to capture and quantify frailty have been described [21-24]. To a varying extent, these methods attempt to identify frailty on the basis of a number of relevant domains, including nutritional status, physical activity, mobility, energy, strength, cognition, mood, and social support [23]. These domains have typically been operationalised in terms of an assessment tool which identifies frailty according to a phenotype (e.g. the presence of 3 or more frailty factors) or cumulative deficits (e.g. on the basis of the presence or absence of variables as a proportion of the total number of items in a frailty index). Some frailty assessment tools may be considered relatively "short, fast and crude" and others "sophisticated" and potentially "time-consuming". It is, therefore, clear that the appropriateness of a particular tool will depend upon the setting, the purposes of the assessment, the background of the assessor and the time available [22, 24]. The majority of the 38 frailty assessment tools identified in a recent systematic review had been applied in a community setting, and among which only two had evidence of reliability and validity that appeared statistically significant, namely: the Frailty Index- Comprehensive Geriatric Assessment (FI-CGA) and the questionnaire-based Tilburg Frailty Indicator (TFI) [24].

For critical care, there are particular challenges. A critically ill patient may be unable to participate in interviews, or to complete questionnaires, or to demonstrate gait speed or grip strength. A reliance on proxies brings into question the validity of responses (compared with those which might have been provided by the patient themselves). Furthermore, it may be difficult to make a distinction between features of acute illness and those better attributed to underlying frailty.

A recent systematic review focused on study of the prevalence and outcomes from critical illness among frail versus non-frail cohorts [25]. The included studies all utilized 
the Clinical Frailty Scale - a 9-point ordinal scale — which may lend itself to the critical care environment, perhaps as one such "short, fast and crude" measure, while four also used a frailty index and two, a frailty phenotype assessment. This review provided useful evidence of the predictive validity of frailty assessment in critically ill populations, with a significant association between frailty and both in-hospital and long-term mortality, as well as increased likelihood of discharge disposition other than home [25].

Moreover, the subsequently published VIP-1 study, including a contemporary cohort of over 5,000 patients over the age of 80 years from 311 ICUs in 21 European countries confirmed that the increasing scores on the Clinical Frailty Scale assessments were independently associated with increased ICU and 30-day mortality, regardless of the elective or emergency nature of the ICU admission [26]. Although the simple Clinical Frailty Scale appears to be a useful adjunct when deciding about ICU admission, the wider psychometric properties of frailty assessment in the critically ill have been under-explored, while the ideal method of assessing frailty in this population is still unclear [27].

\section{FRAILTY MEASUREMENT AS APPLIED TO CLINICAL PRACTICE}

Study of the interplay of age, frailty and critical care outcome has exploded in the last decade, though as yet little appears to have impacted directly on the practice of critical care medicine. For those with a particular susceptibility to the effects of critical illness, in terms of short- and long-term mortality, longer term dependence, disability and quality of life, an understanding of frailty may guide expectations, inform discussions and perhaps aid clinical decision-making. The need is pressing, as although we currently lack a comprehensive business intelligence, the demand on critical care services posed by an ageing population will be hugely significant.

For many patients, the identification of frailty could theoretically trigger a number of interventions, which might include specialist geriatrician input, and/or particular attention to processes relevant to an older population, for example, nutrition, mobilization, and screening for delirium [28]. It is clear, though, that an evidence-base for interventions targeted at the frail critically ill is currently absent.

In the last decade, much effort has gone into promoting the need for co-production of treatment goals on the $\mathrm{ICU}$, though most discussions regarding advanced care and limitation of treatment are taking place with patients who suffer from cancer [29]. Despite the widespread belief that shared decision-making is firmly embedded in clinical practice, a recent French study reported that only $13 \%$ of elderly competent ICU patients had been asked about their treatment preferences [30]. Studies from both North America and Europe also documented that information about a patient's wishes regarding EOL decisions was available in only $20 \%$ of competent patients [31,32]. Outside the Western hemisphere, a recent study of elderly patients in an ICU similarly reported that pre-acute event advance directives were documented in less than $3 \%$ of reviewed cases [33]. It is clear that much work is required to ensure that patients' wishes are systematically sought after in elderly patients, especially since recent data suggests that patients and caregivers in the elderly population are more likely to choose comfort measures and less-intensive treatments, when the prognosis and interventions are explored in detail [29].

Many patients and families are uncertain, and sometimes unwilling to address end-of-life discussions during an acute deterioration leading to hospital admission [31]. However, many will be acutely aware of their increasing frailty and growing dependence on outside help. This common understanding could help the health care providers to initiate these difficult conversations with patients and carers.

Recently, Flaatten et al. [10] compiled a list of ten important critical care trials urgently needed in this field. Thus, the need for greater epidemiological understanding, the lack of objective assessment tools for prognosticating in this group and, possibly most importantly, the lack of understanding on how patients and relatives would view the prospect of ICU admission and the resulting burden, underline the fundamental issues facing our specialisation [10].

\section{CONCLUSIONS}

To the bedside clinician, it is clear that we will deal with an increasing number of older patients. In order to meet and manage the expectations of patients, their families and fellow clinicians, it is likely that critical care will need even greater engagement in the discussion over the goals of care in this population. In practice, this may mean giving informed advice on the description of different treatment modalities, their effects and side-effects, as well as on a probable range of outcomes. This is dependent on healthcare systems in those developed countries particularly affected by the Baby Boom surge and preparing for the coming tide. In particular, with the advent of increasingly integrated electronic health care records, the degree and progression of frailty could theoretically be identified well before the patient needs critical care admission. Though work to demonstrate the validity and reliability of such methods is still at an early stage, the appeal of this while working in an increasingly digital environment is significant. In particular, the early identification of older patients particularly at risk for acute deterioration should provide a timely opportunity to discuss and share goals of care. Rearranging the critical care workflow, incorporating these discussions and identifying the particular needs of a frail 
population much earlier in their journey may significantly help preparations for the impact of an ageing Baby Boom generation on critical care.

\section{ACKNOWLEDGEMENTS}

1. Source of funding: none.

2. Conflicts of interest: none.

\section{References:}

1. Beard JR, Officer A, de Carvalho IA, et al. The World report on ageing and health: a policy framework for healthy ageing. Lancet. 2016; 387(10033): 2145-2154, doi: 10.1016/S0140-6736(15)00516-4, indexed in Pubmed: 26520231.

2. Andrew MK, Rockwood K. Making our health and care systems fit for an ageing population: considerations for Canada. Can Geriatr J. 2014; 17(4): 133-135, doi: 10.5770/cgj.17.163, indexed in Pubmed: 25452826.

3. Davies SC, Winpenny E, Ball S, et al. For debate: a new wave in public health improvement. Lancet. 2014; 384(9957): 1889-1895, doi: 10.1016/ S0140-6736(13)62341-7, indexed in Pubmed: 24703631.

4. Bagshaw SM, Webb SAR, Delaney A, et al. Very old patients admitted to intensive care in Australia and New Zealand: a multi-centre cohort analysis. Crit Care. 2009; 13(2): R45, doi: 10.1186/cc7768, indexed in Pubmed: 19335921

5. Ihra GC, Lehberger J, Hochrieser $\mathrm{H}$, et al. Development of demographics and outcome of very old critically ill patients admitted to intensive care units. Intensive Care Med. 2012; 38(4): 620-626, doi: 10.1007/s00134012-2474-7, indexed in Pubmed: 22354500.

6. Docherty $\mathrm{AB}$, Anderson $\mathrm{NH}$, Walsh $\mathrm{TS}$, et al. Equity of access to critical care among elderly patients in scotland: a national cohort study. Crit Care Med. 2016; 44(1): 3-13, doi: 10.1097/CCM.0000000000001377, indexed in Pubmed: 26672922.

7. Boumendil A, Aegerter P, Guidet B, et al. CUB-Rea Network. Treatment intensity and outcome of patients aged 80 and older in intensive care units: a multicenter matched-cohort study. J Am Geriatr Soc. 2005; 53(1): 88-93, doi: 10.1111/j.1532-5415.2005.53016.x, indexed in Pubmed: 15667382.

8. Lunney JR, Lynn J, Hogan C. Profiles of older medicare decedents. J Am Geriatr Soc. 2002; 50(6): 1108-1112, indexed in Pubmed: 12110073.

9. Heyland D, Cook D, Bagshaw SM, et al. Canadian critical care trials group, canadian researchers at the end of life network. The very elderly admitted to ICU: a quality finish? Crit Care Med. 2015; 43(7): 1352-1360, doi: 10.1097/CCM.0000000000001024, indexed in Pubmed: 25901550.

10. Flaatten $\mathrm{H}$, de Lange $\mathrm{DW}$, Artigas $\mathrm{A}$, et al. The status of intensive care medicine research and a future agenda for very old patients in the ICU. Intensive Care Med. 2017 [Epub ahead of print], doi: 10.1007/s00134017-4718-z, indexed in Pubmed: 28238055.

11. Kaarlola A, Tallgren M, Pettilä V. Long-term survival, quality of life, and quality-adjusted life-years among critically ill elderly patients. Crit Care Med. 2006; 34(8): 2120-2126, doi: 10.1097/01. CCM.0000227656.31911.2E, indexed in Pubmed: 16763517.

12. Blot $S$, Cankurtaran M, Petrovic M, et al. Epidemiology and outcome of nosocomial bloodstream infection in elderly critically ill patients: a comparison between middle-aged, old, and very old patients. Crit Care Med. 2009; 37(5): 1634-1641, doi: 10.1097/CCM.0b013e31819da98e, indexed in Pubmed: 19325489.

13. Biston $P$, Aldecoa $C$, Devriendt J, et al. Outcome of elderly patients with circulatory failure. Intensive Care Med. 2014;40(1):50-56, doi: 10.1007/ s00134-013-3121-7, indexed in Pubmed: 24132383.

14. Sprung CL, Artigas A, Kesecioglu J, et al. The Eldicus prospective, observational study of triage decision making in European intensive care units. Part II: intensive care benefit for the elderly. Crit Care Med. 2012; 40(1): 132-138, doi: 10.1097/CCM.0b013e318232d6b0, indexed in Pubmed: 22001580.

15. Roch A, Wiramus S, Pauly V, et al. Long-term outcome in medical patients aged 80 or over following admission to an intensive care unit. Crit Care. 2011; 15(1): R36, doi: 10.1186/cc9984, indexed in Pubmed: 21261976.

16. Barnato AE, Albert SM, Angus DC, et al. Disability among elderly survivors of mechanical ventilation. Am J Respir Crit Care Med. 2011; 183(8): 1037-1042, doi: 10.1164/rccm.201002-03010C, indexed in Pubmed: 21057004
17. Iwashyna TJ, Ely EW, Smith DM, et al. Long-term cognitive impairment and functional disability among survivors of severe sepsis. JAMA. 2010; 304(16): 1787-1794, doi: 10.1001/jama.2010.1553, indexed in Pubmed: 20978258.

18. Chatila W, Kreimer DT, Criner GJ. Quality of life in survivors of prolonged mechanical ventilatory support. Crit Care Med. 2001; 29(4): 737-742, indexed in Pubmed: 11373458.

19. Smith IE, Shneerson JM. A progressive care programme for prolonged ventilatory failure: analysis of outcome. $\mathrm{Br} J$ Anaesth. 1995; 75(4): 399-404, indexed in Pubmed: 7488476.

20. Clegg A, Young J, Iliffe S, et al. Frailty in elderly people. Lancet. 2013 381(9868): 752-762, doi: 10.1016/S0140-6736(12)62167-9, indexed in Pubmed: 23395245.

21. Apóstolo J, Cooke R, Bobrowicz-Campos E, et al. Predicting risk and outcomes for frail older adults: an umbrella review of frailty screening tools. JBI Database System Rev Implement Rep. 2017; 15(4): 1154-1208, doi: 10.11124/JBISRIR-2016-003018, indexed in Pubmed: 28398987.

22. Buta BJ, Walston JD, Godino JG, et al. Frailty assessment instruments: Systematic characterization of the uses and contexts of highly-cited instruments. Ageing Res Rev. 2016; 26: 53-61, doi: 10.1016/j. arr.2015.12.003, indexed in Pubmed: 26674984.

23. de Vries NM, Staal JB, van Ravensberg CD, et al. Outcome instruments to measure frailty: a systematic review. Ageing Res Rev. 2011; 10(1): 104-114, doi: 10.1016/j.arr.2010.09.001, indexed in Pubmed: 20850567.

24. Dent $E$, Kowal $P$, Hoogendijk EO. Frailty measurement in research and clinical practice: A review. Eur J Intern Med. 2016; 31: 3-10, doi: 10.1016/j.ejim.2016.03.007, indexed in Pubmed: 27039014

25. Muscedere J, Waters B, Varambally A, et al. The impact of frailty on intensive care unit outcomes: a systematic review and meta-analysis. Intensive Care Med. 2017; 43(8): 1105-1122, doi: 10.1007/s00134-0174867-0, indexed in Pubmed: 28676896.

26. Flaatten H, De Lange DW, Morandi A, et al. VIP1 study group. The impact of frailty on ICU and 30-day mortality and the level of care in very elderly patients ( $\geq 80$ years). Intensive Care Med. 2017 [Epub ahead of print], doi: 10.1007/s00134-017-4940-8, indexed in Pubmed: 28936626.

27. Pugh RJ, Thorpe CM, Subbe CP. A critical age: can we reliably measure frailty in critical care? Crit Care. 2017; 21(1): 121, doi: 10.1186/s13054017-1704-3, indexed in Pubmed: 28558806.

28. Hogan DB, Maxwell CJ, Afilalo J, et al. A scoping review of frailty and acute care in middle-aged and older individuals with recommendations for future research. Can Geriatr J. 2017; 20(1): 22-37, doi: 10.5770/ cgj.20.240, indexed in Pubmed: 28396706.

29. Heyland DK, Barwich D, Pichora D, et al. ACCEPT (Advance Care Planning Evaluation in Elderly Patients) Study Team, Canadian Researchers at the End of Life Network (CARENET). Failure to engage hospitalized elderly patients and their families in advance care planning. JAMA Intern Med. 2013; 173(9): 778-787, doi: 10.1001/jamainternmed.2013.180, indexed in Pubmed: 23545563.

30. Lesieur O, Leloup M, Gonzalez F, et al. EPILAT study group. Withholding or withdrawal of treatment under French rules: a study performed in 43 intensive care units. Ann Intensive Care. 2015; 5(1): 56, doi: 10.1186/ s13613-015-0056-x, indexed in Pubmed: 26092498.

31. Scheunemann LP, Cunningham TV, Arnold RM, et al. How clinicians discuss critically ill patients' preferences and values with surrogates: an empirical analysis. Crit Care Med. 2015; 43(4): 757-764, doi: 10.1097/ CCM.0000000000000772, indexed in Pubmed: 25565458.

32. Cohen S, Sprung C, Sjokvist $P$, et al. Communication of end-of-life decisions in European intensive care units. Intensive Care Med. 2005; 31(9): 1215-1221, doi: 10.1007/s00134-005-2742-x, indexed in Pubmed: 16041519 .

33. Kim J, Choi SMi, Park YS, et al. Factors influencing the initiation of intensive care in elderly patients and their families: A retrospective cohort study. Palliat Med. 2016; 30(8): 789-799, doi: 10.1177/0269216316634241, indexed in Pubmed: 26934945.

\section{Correspondending author:}

Tamas Szakmany

Critical Care Directorate

Royal Gwent Hospital

Cardiff Road, Newport

NP20 2UB, United Kingdom

e-mail: szakmanyt1@cardiff.ac.uk 